\title{
Diabetes Podcast: Do It Yourself/Open Source Artificial Pancreas Systems: Part 1
}

Sufyan Hussain · Dana Lewis

Received: April 23, 2020 / Published online: June 3, 2020

(C) The Author(s) 2020

Victoria Glasson (VG)

Sufyan Hussain $(\mathrm{SH})$

Dana Lewis (DL)

VG: Hello my name is Victoria Glasson and I am the Managing Editor for Diabetes Therapy. Welcome to our Technology in Diabetes podcast. Today we will be talking with Dr. Sufyan Hussain, consultant physician in diabetes and endocrinology and honorary senior lecturer at Guy's and St Thomas' NHS Foundation Trust and Kings College London. He will be speaking with Dana Lewis, founder and developer of the open artificial pancreas system (APS).

SH: Hello Diabetes Therapy, I am Sufyan Hussain. I am a diabetes and endocrine physician and honorary senior clinical lecturer in one of the UK's leading type 1 diabetes (T1D) teams.

Digital Features To view digital features for this article go to https://doi.org/10.6084/m9.figshare.12179103.

Electronic Supplementary Material The online version of this article (https://doi.org/10.1007/s13300020-00827-9) contains supplementary material, which is available to authorized users.

S. Hussain

Guy's and St Thomas' NHS Foundation Trust, London, UK

S. Hussain $(\square)$

King's College London, London, UK

e-mail: Sufyan.hussain@kcl.ac.uk

D. Lewis

OpenAPS, Seattle, WA, USA
I have lived with T1D for nearly 30 years and I am naturally really excited by anything to do with it. With the team at Diabetes Therapy, we will be taking you through some exciting aspects of T1D and diabetes technology with some very special guests. I look forward to learning more and I am really interested in your comments using the hashtag \#T1Dpodcast.

It's the 27th of November 2019, and today I am joined by the wonderful Dana Lewis. Dana is joining us from Seattle. She is a co-creator of the 'Do it yourself' (DIY) artificial pancreas system and is also the author of the e-book Automated Insulin Delivery: How artificial pancreas "closed loop" systems can aid you in living with diabetes, the only book around for artificial pancreas systems [1]. Today's session will be focussing on the journey of how the 'Do it yourself' APS came about, where we're at and the next steps for all involved in the type 1 community. Before I get Dana to speak, I will tell you about my interactions with Dana before this (podcast). I have met Dana once in person in London in 2016, and we have spoken by Skype and worked on a few things since. The one thing I always remember about Dana is her super positive energising buzz and attitude for helping others, which she calls 'paying it forward'. Dana, how are you?

DL: I am doing well. Thank you so much for having me on the podcast. 
SH: Great! It's really super exciting for us to have you and learn about the DIY/APS movement. Before we do that, please tell us a bit about yourself.

DL: I was actually diagnosed with T1D at the age of 14 and have now lived with it for many years and have seen the evolution of technologies from a finger stick and multiple daily injections to using an insulin pump, using a continuous glucose monitor (CGM) and now using what we call closed loop therapy. I am an American, I live in the United States and I come from a communications background, but I have spent more and more of my time in the last couple of years researching and working on the side in the diabetes space.

SH: So DIY? How did you start this?

DL: So DIY stands for 'Do it yourself', which is actually what diabetes is. Diabetes is so selfmanaged by people with diabetes; we do $99 \%$ of everything on our own. So when people ask me about DIY, they are usually asking about DIY diabetes technology; and my journey in that space started when I was frustrated with not being able to hear my continuous blood glucose monitor alarm and wanted to find a way to make a louder alarm. I was not satisfied with the response from the companies saying that I was the only one with this problem or it would be out in a couple of years in the next version. I was able to spot a solution that somebody else created.

John (Costik) had created a way to remotely monitor his CGM data, and I asked him to share his code. He said yes, which enabled me to take my CGM data, put it in the cloud, make a louder alarm and send it down to my phone. From there we added this algorithm to do decisionmaking in the future and have an open looped system, although we did not know it at the time. By talking with others and sharing what we had done, we met somebody else named Ben West who had figured out how to remotely communicate with some of the older insulin pumps, and a few weeks after that when we realised we had the ability to talk to the pumps, the ability to talk to the CGM, we built an algorithm that decides what needs to be done. We could close the loop and automate, adjusting the insulin delivery; so that's what we did [2].

SH: Wow that sounds really exciting. Talk us through the steps. How was your reaction and the reaction of others who started working on these?

DL: My reaction was a lot of "oh wow, I feel really empowered to solve my own problem". Maybe not everyone else has this problem, but it is definitely something affecting my quality of life so I want to do it for me and its worth sharing. If it helps one other person sleep safely and confidently through the night then it's worth it. My reaction is one of empowerment and positivity and joy because this is really helping me, and other people's reactions range from scepticism to also positivity of them wanting to explore doing their own DIY solution and seeing if it works for them.

SH: Really exciting stuff. As you rightly say, diabetes has always been about DIY and applying things to your own personal self and learning and empowering yourself with the knowledge that is out there. This is such a huge step forward in how the creative capital of people has come together and worked to make lives of each other much better by sharing and open source collaborative approaches. It's a really unique example. How did it all spread? It's gone from working with a few people to now going almost viral, with a lot of people being aware of this worldwide, and certainly the community is growing.

DL: I think you've said it exactly right. It's a story of people coming together. I think it's really easy when telling a story about technology to latch onto one person's story and because I've been public about my story, my story is the one that is often told. But this is the story of a community project; I was helped by John, helped out by Ben and we collaborated with the community to build the solution and continued to work on it for over a year. There's dozens-if not hundreds-of people who have played a role, and I think it's really neat because it is not that this type of technology was not known to industry or was not known to researchers, but we were in the right place at the right time. Social media enabled us to share what we are doing, share our ideas and come 
together to problem solve, and the diabetes technology was also there because we are using existing, commercially approved pumps and CGM with off-the-shelf hardware to bridge the communication between these devices. I think it is really cool because the community came together to solve problems, and people also learn about this through their own local communities or from online communities. This is how it spread in both the diabetes community and through healthcare providers, but also by word of mouth.

SH: Wow, would you like to know what my initial reactions were when I first found out about the movement? My initial reactions when I heard about it from people or online or from people in my clinic were that it sounds too good to be true. Is this a cult? It seems a bit techy. Not for me and my minimalist lifestyle, set in my routines. I think as I learnt more about it and after your talk in 2016 that I got thinking very differently. Until then I was working in something called co-production, which was about valuing our citizens, co-working with people and lay members to improve health care. There was a lot of talk about harnessing technology to improve health outcomes through these sorts of crowd sharing and open source collaborative approaches coming from think tanks like King's Fund [3] and Nesta [4] in the United Kingdom and about how this would be a solution for healthcare in the years to come. I also heard such talk at that time, and I thought "great stuff from the ivory tower". So when I actually heard your talk I thought "wow", this is amazing how people have come together and made something so clever and got well ahead of where the technology sector is and where academia has been and have learnt from the ideas that came out and have applied it and used it. I think as I have learnt more about it and got to know more from people using it and gained a lot more insight, I have been really taken aback by the level of sophistication on the ease of use, how intuitive it is, how many layers of safety have been put in and the actual intricacies of the code. So I have been very surprised since I first started to get to know it really well about a year ago. At that time, I thought I've got a $\mathrm{PhD}$, 15 years of experience of being a doctor, almost
30 years of being a type 1 diabetic and using pumps etc. I've kind of seen it all, but really after learning and seeing how the APS works and how it adjusts things, it has given me a very different insight on to how to manage people with T1D in complex situations. For me it's been a fascinating insight. Learning from community projects is something I think is a great model for healthcare, not just for T1D, but a great model for healthcare to embody.

DL: I think it really just shows how hard diabetes is and how much we don't know about it. Because for a lot of people, quality of life is so low and so challenging that even if you're lucky enough to have access to insulin and have access to tools like pumps and CGM, we're still tasking human brains with doing the work of a highly evolved organ, the pancreas, and since the brain is also being tasked with other things, it's hard work. So, I think that one of the really interesting things that people don't realise is we made small changes over time; we tackled each problem as we found it or each thing that we wanted to improve; and we tweaked and we tried. In some cases we failed and tried again to solve the problem and by making those small changes in the direction, those changes became multiplicative instead of additive. It made a huge difference being able to solve one thing at a time. It's like the phrase some people say 'How do you eat an elephant? Well, one bite at a time'. When we look at diabetes it is very easy as healthcare providers or as patients to be overwhelmed as there are so many variables that come into play with adjusting blood sugars and impacting blood sugars, but once you have this type of technology it automates a lot of the work and brings better glycaemic results so that you can then spot new problem areas that you did not think were solvable before. I think that's one of my favourite parts about where this technology is heading. It's not just that we automated insulin delivery, which in itself is amazing. It's not just about the fact that we were able to do this before commercial technology came about. But what I'm most excited about is that we've not stopped learning, not in the process of technology development but also not about diabetes. We're still discovering new things as we've automated and reduced so 
much of the noise that we're finding out new things about how diabetes works in people with T1D. It is really cool and kind of unexpected that patients would be the ones able to reduce the noise and identify where these problem areas are.

SH: That's so true, and I think the example you highlight in your book, namely the illustration you've shown about manual diabetes to automated diabetes sums it up so nicely [5]. It's something that I use a lot and try to use when I am explaining T1D to people when they don't understand the intricacies behind it. It's 24/7, it's constant, and it requires a lot of thinking, planning, insight, foresight and knowledge about how to adjust things. To live your life as a carer for kids or a full-time worker or a shift worker or doing all of these things together as well as driving, doing activities that may or may not be planned; you can imagine how much variation could occur from within your diabetes. What this gives you is the flexibility and automation that allows you to do more and gives you the capacity to do it without thinking about it all the time.

DL: Exactly, and there are probably a dozen or more reasons why someone would choose automated insulin delivery. It's not going to be for everyone because not everybody wants to wear a pump and CGM-and that is totally fine. Some people will say okay, I'm willing to wear a pump and CGM already, but I'm getting my target A1c so what is the benefit for me? Especially if you look in the online patient communities, you see story after story of people saying yes I was getting my target A1C, but I was doing so much work, my loved ones were doing so much work, it takes up so much time, energy and effort to achieve that result. So now I'm getting the same result but working less to achieve it. That quality of life benefit alone is super high. This is probably a small portion of the people who are choosing to use automated insulin delivery, as there are many people who despite their best efforts are not able to achieve their target A1c and glycaemic variability levels. It can make a big difference in helping people achieve those results. The ripple effect on everything from having more time to sleeping better, feeling better, having more energy and being able to live your life more fully is just incredible.

SH: Absolutely, and we see this in the US type 1 registry data as well [6]. We hope that increasing the use of technology improves the quality of life and hopefully reduces hypos and improves flexibility, but despite the increasing use of technology, it doesn't always mean you end up getting the glycaemia you aspire to get. I think that's where your point really comes in. Trying to navigate and use these tools alongside the complexity of life. Life has become a lot more challenging over the years, and we have a lot more burdens coming from different directions, and that's really where automation comes in.

DL: I think one thing is that we often assume we will add technology on and expect a human to do the same things. For example, carb counting and meal announcing as well as bolusing or injecting before meal times. However, through the automation and advancement of this technology, we're now at the point, at least in the DIY community, where some of us have the choice of whether or not to carb count, whether or not to announce a meal, whether or not we should bolus fully or partially before a meal. These choices suddenly change the landscape of diabetes and the way we do healthcare because instead of people being shamed and blamed for so many of the behaviours they're being tasked to do, including the ones around meal time, they are able to say okay, we can quantify the impact of choosing to do a meal bolus or not or of choosing to take meals or not with a particular type of closed loop system and then look at the time in range difference and the A1C difference from those patterns of behaviour and decide is it worth it? For a lot of people that's going to be a game changer in their relationship with their diabetes and their relationship with healthcare providers. Instead of feeling dread at going to visit the healthcare provider and feeling like they are always being told they are doing something wrong, a more productive conversation can take place on the type of trade-offs between particular behaviours and the glycaemic benefit or the benefit to quality of life by choosing to do or not to do different behaviours that we used to 
think were non-negotiable. I'm really excited about that being the future of diabetes care and being able to quantify these trade-offs; I think that provides a lot more freedom and flexibility beyond what many in the diabetes world think is possible right now.

SH: One of the things that I thought I'd pick up on is the terminology around artificial pancreas systems. Obviously the artificial pancreas system is a great catch word. Having a scientific background myself, [I know] the pancreas is a clever organ that does many different things. Some of the terminologies that are now used in the literature are hybrid closed loops and automated insulin dosing systems, and I do not know which you would prefer. How would we term this particular type of system as things evolve for the future?

DL: I think it's hard, and that's a part of why I named my book very carefully because some people prefer the term artificial pancreas whereas others say no, it's not fully replacing the pancreas, it's a closed loop system. But then people don't recognise what the difference is between a hybrid and fully closed loop. Some people think a loop is only fully closed if it's a multiple drug system versus a single hormone system. So I think it's complicated, and there's a lot of different names, but it's good to be clear with the terminology we're using. It's also hard because there are different DIY systems and different commercial systems, and they are not all hybrid closed loops. Some systems have fully closed loop capabilities if the users choose to use them that way and that's where this technology is eventually heading. I think one of the challenges is that most of the general public do not realise that insulin pumps aren't already closed loop; many people think insulin pumps adjust to changing glucose levels and that standard insulin pumps do not. So I think that even within the diabetes community there is confusion among the general public. It's therefore good to be upfront about this technology we're talking about and the interaction that the human has to have with this system which, for example, is greater if you have a hybrid closed loop rather than a fully closed loop.

$\mathrm{SH}$ : I think that's very true. I think there are common misconceptions around even what pumps do; a question sometimes directed to physicians by the general public is whether pumps measure sugars. So yes, I think there are a lot of misconceptions out there, and you're right, terminology is important. From my perspective as a healthcare professional, I like people who are using the system to understand that it is an automated insulin dosing system and that the automated code is going to be reliant on glucose data to then give insulin in a coded manner; this in turn will be reliant on certain assumptions and will also require some level of manual input depending on how closed the system is. That's what I try and get them to consider in order to get them thinking that it's not going to be a quick fix that once working will solve everything; rather, it's something that they will have to learn to use and learn to understand how it works in order to adapt it into their life. Yes, it will make their life easier, but there are certain things that they will need to learn before they get into it and certainly things they will need to learn as they use it. What are your thoughts on this Dana? Is that the right way of thinking as a clinician?

DL: I think for patients and clinicians it's important to understand that there's a learning curve with any new type of technology. I often tell people it's like switching from multiple daily injections to an insulin pump. There's a learning curve there, and you have to adjust your setting and change the way you work with that different type of technology. Switching from manual to automated insulin delivery where the system is automated you're also going to have to change your behaviours and to change how you interact with it. It is automated, but like you said it's not a cure, and so once you get it up and running and you get over that initial learning curve you shift your focus from having to think ahead and do the work yourself (with regards to managing the blood sugars), to keeping the systems working. For example, making sure your insulin pump site is correctly sited on your body and that the insulin is absorbing well, and things like keeping your CGM sensor working accurately. The tip that I often give to people who are thinking about shifting to automated insulin delivery, or who are just getting started, is to remind them 
to plan ahead so that when their sensor session dies, ideally it's not going to be in the middle of the night or not immediately before or during the middle of a large meal. These are the little things and the shifts in thinking that must be given attention; it makes a big difference, but it's important for people to figure out how to work with this new technology and not to begin assuming they are going to do the same as what they did before or that they can quit doing everything they did before because the system will do it for them. Well it can't do everything, it's not a cure. You have to maintain the site and the sensor and keep the system running. So it is a different type of work and thinking, and I think making sure that both patients and providers are aware of the expectations and of what that learning curve looks like is really important [7].

SH: Great, I am pleased I am on the right lines. As you rightly say, as you get the system in place and you get it working it makes that manual process a lot more automated and hopefully less challenging. It's great how it's helping people with T1D, but what have been the challenges and the barriers in terms of seeing this type of technology being used and seeing the spread of it?

DL: I think it depends on whether we talk about the technology as a general concept or we're talking specifically about DIY. I think there are some challenges specific to DIY in terms of you have to do it yourself, you are in charge of it and if it breaks you must fix it, among others. I think in general, getting healthcare providers to understand automated insulin delivery is going to take awhile. I think patients are very, very excited about this technology, but I think healthcare providers will also have to change the way they work and interact with patients using this technology. I think the change in education and change in approach to healthcare that will shift as a result of that is going to be one of the challenges as people want to adapt this technology. I think patients will continue to play a role in helping to educate providers and bringing this technology to them, but I also hope we can speed up the education that is coming from the traditional channels that typically inform healthcare providers on new technology. I think this technology is coming; it's been 5 years since I closed the loop for myself, and several years since there have been at least one or two commercial options coming on the market in more countries so it's definitely time. I also think we need to make sure the education system supports healthcare providers who are going to be supporting more and more patients using this technology.

SH: Yes, absolutely, and as a clinician, even now with more regulated systems on the horizon, you're right that understanding how we approach automated insulin dosing systems or artificial pancreas systems-(understanding) how do we use them and how do we implement them-is going to be the next big step. Those of us involved in supporting individuals with the DIY/APS have certainly learnt a lot. I think we will be a little ahead of the curve as a result of that, and for those listening, whether they have T1D or are healthcare professionals, I think there's a number of resources. Dana, I'm sure you can help me quote some of them, but one I would like to bring up is your book, which I think sums up a lot of aspects really nicely about where to start, how APS works, where to go next in terms of research as well practical applications, such as how to use it, and what sort of learning aspects are required. I think your book covers a number of elements really nicely. Your book 'Automated Insulin Delivery: How artificial pancreas "closed loop" systems can aid you in living with diabetes' is a free book to access, am I right Dana? [1]. (A free version of the book can be accessed at https://www. ArtificialPancreasBook.com.)

DL: Thank you for bringing it up. Yes, it is available for free online. It can be downloaded as a PDF for those who want it on kindle or print copies can also be ordered. The book content is open source so it can be freely used and can also be adapted. For example, there is a chapter on research and a chapter for healthcare providers. I have had many patients from the DIY community saying that they have sent the link from the healthcare provider chapter to their own doctor and asked them to read it as a source of background, so it is great to see it being used in that way. But, reading the whole book would be 
educational for any healthcare provider who is relatively new to closed loop space technology. Although it is written for people with a knowledge of diabetes, both patients and healthcare providers, it is written with the hope of helping everybody (to) really understand the broader concepts behind this technology, such as the learning curve we talked about when shifting to automated delivery. Hopefully the book will increase the comfort level of people when they have the opportunity to choose or think about whether they want to use this type of technology in the future, whether it's DIY or a commercial system, that they feel like they have a better understanding and are more equipped to make their choices.

$\mathrm{SH}$ : Focussing a little more on challenges and barriers, one of the challenges for us as healthcare professionals has been coming from regulation and accountability $[8,9]$. What are your thoughts about the regulation and accountability aspect and how we support it in the clinical domain and how we get past this issue, which is clearly holding up a lot of healthcare professionals from openly supporting or using this technology or getting more involved in it?

DL: I think that's a great question. I think one of the helpful ways to frame this issue and the associated concern is not to think about regulation as a rubber stamp, but rather to think about it as a process for embedding and deciding if you can trust this technology to do what it claims to do. That's really what regulation is about. DIY is unregulated because it has not gone through the regulatory process, but it's completely transparent, it's openly available to anyone, patient or doctor, and everyone can study the code and documentation, learn the system and query the system or developers about any concerns or issues they have. I think that more healthcare providers should be be critical and question commercial systems and not just accept a rubber stamp of approval, or not, asking the companies more questions about how the technology works on behalf of patients. I think as a patient its very challenging to be given a black box and told here you go, there are two or three knobs on this black box, trust it, it'll work eventually once it learns you, but we're not going to tell you how it learns you or how you should change your behaviours over time as it learns you or not. I think commercial technology is challenging due to a lack of transparency and because you are being asked to rely solely on the regulatory approval. That removes the learning process and trust development from an individual and from the healthcare provider, and that's really challenging. I hope more healthcare providers push for transparency and more detail on how any system works, DIY or commercial. I hope that the industries start to provide more details about how their system works so people can best use it in their everyday life. The other thing that healthcare providers who might have patients starting on this technology should think about is that patients do off-label things all the time with their devices; for example where they wear their CGM sensors on their body. Many people wear these sensors on off-label parts of their body. As a healthcare provider, you might say this sensor has only regulatory approval for this part or that part of the body and be aware that it has not been tested there, but I see you're getting good results and reasonable accuracy in this sensor so it's okay. I think that's the same type of conversation we should be having about this technology. If a patient comes in and they clearly understand it, they've done their research, they are using it well and getting good results, [the response] shouldn't be 'this is not approved I can't talk about it' but rather the response should be a conversation about how it's off label and that even if you don't understand it yourself and can't help with this technology, that is totally fine. I think there is a difference between being open about concerns or open about not understanding the technology, versus shutting down (the conversation) because it's not a regulatory-approved solution or refusing to see or care for that patient because they are choosing to do something that you don't necessarily agree with.

SH: Thanks Dana that's a really helpful insight. I think there is a major lesson for all industries really; the tech industries as well as healthcare in general could be more understanding about how to be more centred towards people using technologies as well as healthcare technologies. A lesson for all of us that will 
hopefully allow more things in the future to be applied with more ease as the creative capital of people come together and engineer solution like these. In terms of research that's also been one of the question marks surrounding DIY/APS systems. I guess DIY/APS doesn't have the commercial power and money to construct large randomised controlled studies, and with ethics requirement, research and trials become even more challenging. Has any research been done on the DIY/APS?

DL: The first research was actually a self-reported study for the community which we presented at ADA (American Diabetes Association) scientific sessions back in 2016 [10], and the response was mixed from healthcare providers between 'wow, this is really neat, and it's great to see some data' and 'that is self-reported data, it would be much better if you analysed the raw data'. So, in the years following we did a study that went received approval from a university ethics board, and we retrospectively analysed and presented the raw data, saw the same general trends [11] and got the same response, with again $50 \%$ of people said 'this is great to see the data' and $50 \%$ of people also saying 'well, its retrospective, it would be much better if it was observational prospective' [12-14]. Well guess what has happened since? There have been observational [15-17] trials. In addition, Koutsovasilis et al. [18] at the European Association for the Study of Diabetes (EASD) meeting recently presented data from a prospective trial in which 23 patients had been put on one of the DIY open source closed loop systems; the data were just like the data from all the other studies, and people then said 'that's great, but that's not randomised', and randomised is the ultimate gold standard of everything. Well guess what? There has been a randomised control trial that has been approved and funded and is commencing recruitment in 2020 in New Zealand [19]. The community has worked with researchers and done research ourselves at all of these different stages. I think that in some cases the pushback of 'well, we need research in order to back this' is a little bit of a straw man argument for 'this is different and this is something we're not comfortable with, so we're going to try to throw up barriers'; but not everybody is doing that. I think it was good to have faced these challenges because it led us to conduct a lot of these studies and trials and data analyses. However, it's really quite telling if you compare the research outcomes [20], and I can cite several studies [21] that have been done around the world in different populations. There's a lot of perceptions of the community of very engineering and tech savvy adults that's using DIY technology [see https://openaps.org/outcomes/ where lots of these studies are listed]. Well no, it's not like that. There's a study done by the OPEN consortium called the DIWHY study [22] about who is actually using this technology and why are people using it? [23] There's a variety of different types of people using it from different socioeconomic backgrounds and different tech levels of experience. I think it's interesting we're seeing more research show up in this space, but I would also again, in terms of scrutinising the DIY technology, also scrutinise commercial technology more carefully. I think we should do the same thing with all research around closed loop systems and encourage more researchers and more industry-directed research to examine the following questions: What are the barriers to this technology? What is the ease of use? How do people learn how to understand it? How are they using it? What are the ups and downs to using it? All of these are questions that we are asking about DIY research. I think we should encourage more research with commercial technology in the hope of getting the systems to evolve and address those things in the way that the DIY technology has evolved to address the concerns of both the patient community and broader community over time.

SH: Really great insight Dana. You have given us lot of food for thought about how the scientific and medical community needs to reflect, look back and review what it calls 'research'. Certainly for me as a clinician with a strong academic background and having moved into the clinical arena, I really value the realworld evidence that you see being presented and real-world scenarios much more highly sometimes than data from randomised controlled trials which are sometimes designed in a manner which may attract certain types of 
people more and may not replicate exactly what happens in your clinical environment. I think what you've said provides a great insight in terms of how outcomes are reported, and it's great that reporting is open and the data are freely accessible and not hidden or tucked away. So I am hopeful we will see more exciting things from these studies soon.

DL: Absolutely and I will also point out that we developed the OpenAPS Data Commons [24] to gather data anonymously for the community and for research to encourage more research in diabetes and to encourage people with new ideas to do this research. If you're interested in doing research and checking out the data check out the OpenAPS Data Commons because that is also a tool that we as the community have made available back to the research community as well.

VG: Due to the length of the podcast we have chosen to split the podcast into two parts. Part two will be released next week!

You can listen to more podcasts by subscribing to Adis Rapid + podcast with your preferred podcast provider, or by visiting the website. A full list of declarations, including funding and author disclosure statements can also be found on the website.

\section{ACKNOWLEDGEMENTS}

Funding. No funding or sponsorship was received for this study or publication of this article.

Authorship. All named authors meet the International Committee of Medical Journal Editors (ICMJE) criteria for authorship for this article, take responsibility for the integrity of the work as a whole, and have given their approval for this version to be published.

Disclosures. Sufyan Hussain has received non-promotional educational speaker and/or advisory services for Medtronic, Roche, Dexcom, Abbott and Novo Nordisk. Dana Lewis has nothing to disclose.
Compliance with Ethics Guidelines. This article does not contain any studies with human participants or animals performed by any of the authors.

Peer Review. Please note, contrary to the journal's standard single-blind peer review process, as an editorial this article underwent review by the journal's Editor-in-Chief.

Data Availability. Data sharing is not applicable to this article as no datasets were generated or analyzed during the current study.

Open Access. This article is licensed under a Creative Commons Attribution-NonCommercial 4.0 International License, which permits any non-commercial use, sharing, adaptation, distribution and reproduction in any medium or format, as long as you give appropriate credit to the original author(s) and the source, provide a link to the Creative Commons licence, and indicate if changes were made. The images or other third party material in this article are included in the article's Creative Commons licence, unless indicated otherwise in a credit line to the material. If material is not included in the article's Creative Commons licence and your intended use is not permitted by statutory regulation or exceeds the permitted use, you will need to obtain permission directly from the copyright holder. To view a copy of this licence, visit http://creativecommons.org/licenses/bync/4.0/.

\section{REFERENCES}

1. Lewis D. Automated Insulin Delivery: how artificial pancreas "closed loop" systems can aid you in living with diabetes. 2019. https://www.amazon.com/gp/ product/B07R6VJJTH/ref=as_li_tl?ie=UTF8\&camp= $1789 \&$ creative $=9325 \&$ creativeASIN $=$ B07R6VJJTH\&l inkCode=as2\&tag=diyps-20\&linkId=943eac0db258 0e0a6a21af4cb15c8d99. Accessed Nov 2019.

2. Lewis D. History and perspective on DIY closed looping. J Diabetes Sci Technol. 2019;13(4):790-3.

3. The King's Fund. Shared responsibility for health: the cultural change we need. 2018. https://www. kingsfund. 
org.uk/publications/shared-responsibility-health. Accessed Nov 2019.

4. Nesta. The NHS in 2030: a vision of a people-powered, knowledge-powered health system. 2015. https://media.nesta.org.uk/documents/the-nhs-in2030.pdf. Accessed Nov 2019.

5. Lewis DM. How APS works. Automated insulin delivery: how artificial pancreas "closed loop" systems can aid you in living with diabetes. 2019. https://www.artificialpancreasbook.com/1.-whatsa-closed-loop-or-artificial-pancreas-system-and-whywould-someone-use-one\#how-aps-works. Accessed Nov 2019.

6. Foster NC, Beck R, Miller K, et al. State of type 1 diabetes management and outcomes from the T1D exchange in 2016-2018. Diabetes Technol Ther. 2019;21(2):66-72.

7. Lewis D. Setting expectations for successful artificial pancreas/hybrid closed loop/automated insulin delivery adoption. J Diabetes Sci Technol. 2018;12(2):533-4.

8. Marshall DC, et al. Do-it-yourself artificial pancreas systems in type 1 diabetes: perspectives of two adult users, a caregiver and three physicians. Diabetes Ther. 2019;10(5):1553-64. https://doi.org/10.1007/ s13300-019-00679-y.

9. Jennings $\mathrm{P}$, et al. Do-it-yourself artificial pancreas systems: a review of the emerging evidence and insights for healthcare professionals. J Diabetes Sci Technol. 2019. https://doi.org/10.1177/193229681 9894296.

10. Lewis D, Leibrand S. Real-world use of open source artificial pancreas systems. J Diabetes Sci Technol. 2016;10(6):1411.

11. Lewis DM, Swain RS, Donner TW. Improvements in A1C and time-in-range in DIY closed-loop (OpenAPS) users. Diabetes. 2018. https://doi.org/10.2337/ db18-352-OR.

12. Melmer A, Züger T, Lewis DM, Leibrand S, Stettler C, Laimer M. Glycemic control in individuals with type 1 diabetes using an open source artificial pancreas system (OpenAPS). Diabetes Obes Metab. 2019;21(10):2333-7. https://doi.org/10.1111/dom. 13810.

13. Lee JM, Newman MW, Gebremariam A, et al. Realworld use and self-reported health outcomes of a patient-designed do-it-yourself mobile technology system for diabetes: lessons for mobile health. Diabetes Technol Ther. 2017;19:209-19. https:// doi.org/10.1089/dia.2016.0312.

14. Braune $\mathrm{K}$, O'Donnell S, Cleal B, Lewis D, Tappe A, Willaing I, et al. Real-world use of do-it-yourself artificial pancreas systems in children and adolescents with type 1 diabetes: online survey and analysis of self-reported clinical outcomes. JMIR MHealth UHealth. 2019;7:e14087. https://doi.org/ 10.2196/14087.

15. Provenzano V, Guastamacchia E, Brancato D, et al. Closing the loop with OpenAPS in people with type 1 diabetes-experience from Italy. Diabetes. 2018;67(Suppl 1). https://doi.org/10.2337/db18993-P.

16. Choi SB, Hong ES, Noh YH. Open artificial pancreas system reduced hypoglycemia and improved glycemic control in patients with type 1 diabetes. Diabetes. 2018;67(Suppl 1). https://doi.org/10. 2337/db18-964-P.

17. Petruzelkova L, Soupal J, Plasova V, et al. Excellent glycemic control maintained by open-source hybrid closed-loop AndroidAPS during and after sustained physical activity. Diabetes Technol Ther. 2018;20(11):744-50. https://doi.org/10.1089/dia. 2018.0214.

18. Koutsovasilis et al. Clinical evaluation of a closedloop insulin delivery system on glycaemic control in adults with type 1 diabetes. In: European Association for the Study of Diabetes (EASD) virtual meeting. 2019. https://www.easd.org/virtualmeeting/ home.html\#!resources/clinical-evaluation-of-a-closedloop-insulin-delivery-system-on-glycaemic-control-inadults-with-type-1-diabetes-134c4ad2-53f1-4698927f-5bd287a76a5d.

19. University of Otago. The CREATE Trial. 2019. https://www.otago.ac.nz/christchurch/department s/paediatrics/research/otago717634.html. Accessed Nov 2019.

20. Melmer A, Züger T, Lewis D, Leibrand S, Stettler C, Laimer M. Glycemic control in individuals with type 1 diabetes using an open source artificial pancreas system (OpenAPS). Diabetes Obes Metab. 2019;21(10):2333-7. https://doi.org/10.1111/dom. 13810.

21. Toffanin C, et al. In silico trials of an open-source android-based artificial pancreas: a new paradigm 
to test safety and efficacy of do-it-yourself systems. Diabetes Technol Ther. 2019. https://doi.org/10. 1089/dia.2019.0375.

22. The Open Project. DIWHY n.d. 2019. https://opendiabetes.eu/research/diwhy/. Accessed 18 Oct 2019.

23. Braune $\mathrm{K}, \mathrm{O}^{\prime}$ Donnell S, Cleal B, et al. Real-world use of do-it-yourself artificial pancreas systems in children and adolescents: self-reported clinical outcomes. JMIR mHealth UHealth. 2019;7(7): e14087. https://doi.org/10.2196/14087.

24. OpenAPS.Org. OpenAPS Data commons. 2019. https://openaps.org/data-commons/. Accessed 22 Aug 2019. 